Toffoli, P., Khodadad, P., Rodier, N. \& Viossat, B. (1987). Acta Cryst. C43, 2048-2050.

Williams, A. F., Flack, H. D. \& Vincent, M. G. (1980). Acta Cryst. B36, 1204-1206, 1206-1208.

Acta Cryst. (1994). C50, 996-997

\section{A Revised Structure for $\alpha$-Dicalcium Silicate Hydrate}

\author{
RICHARD E. MARSH \\ The Beckman Institute, $\uparrow$ California Institute of \\ Technology, Pasadena, California 91125, USA
}

(Received 16 November 1993; accepted 8 February 1994)

\begin{abstract}
The structure of $\alpha$-dicalcium silicate hydrate, $\mathrm{Ca}_{2}\left(\mathrm{SiO}_{3} \mathrm{OH}\right)(\mathrm{OH})$, has recently been described and refined [Yano, Urabe, Ikawa, Teraushi, Ishizawa \& Udagawa (1993). Acta Cryst. C49, 1555-1559] in space group $P 22_{1} 2_{1} 2_{1}$ (orthorhombic; $a=9.487$ (4), $b$ $=9.179(4), c=10.666(7) \AA, Z=8)$. It is better described in Pbca. Revised coordinates are given.
\end{abstract}

\section{Comment}

In their report of the structure of $\mathrm{Ca}_{2}\left(\mathrm{SiO}_{3} \mathrm{OH}\right)(\mathrm{OH})$, Yano, Urabe, Ikawa, Teraushi, Ishizawa \& Udagawa (1993) noted that 'most of the reflections matched the extinction rules consistent with (space group) $P b c a$ ', but that some 'very weak' violations were detected. They further noted that least-squares refinement in $P b c a$, with isotropic $B$ values, led to $R$ $=0.073$, after which 'the space group was altered to $P 2_{1} 2_{1} 2_{1}$; no mention is made as to how the inherent singularities were avoided. The resulting structure, although generally reasonable, showed relatively large e.s.d.'s for so hard a crystal $(0.01-0.02 \AA$ in the positions for the $\mathrm{O}$ atoms) and surprisingly large variations in presumably equivalent bond lengths and angles. Perhaps even more disturbing were the large discrepancies between the $U_{i j}$ values of equivalent atoms; for example, $\mathrm{Ca}(3)$ showed $U_{\text {eq }}=$ 0.0020 (9) $\AA^{2}$ while the structurally equivalent atom $\mathrm{Ca}(4)$ showed $U_{\text {eq }}=0.0131(7) \AA^{2}$. Since such manifestations are typical of attempts to refine a centrosymmetric structure in a non-centrosymmetric space group, a further consideration of space group $\mathrm{Pbca}$ seemed appropriate.

$$
\uparrow \overline{\text { Contribution No. } 8896 .}
$$

A listing of $1677 F_{o}$ and $\sigma\left(F_{o}\right)$ values was obtained from SUP 71140. Included were six reflections $0,17,6,10,0,7,16,0,9,10,0,11,15,2,0$ and $7,11,0-$ forbidden in $\mathrm{Pbca}$. The largest of these had $F_{o} / \sigma\left(F_{o}\right)$ $=4.2$, which corresponds to $I / \sigma(I)=2.1-$ a truly marginal observation. [The authors reported that the 1677 'non-zero' reflections had $I>3 \sigma(I)$, but apparently the cutoff was lower, at $F_{o}>3 \sigma\left(F_{o}\right)$ ]. In the face of the approximately 200 other space-group violators that lay within the sphere of reflection and were indeed unobserved, the apparent presence of these six very weak violations - which could well have resulted from double reflection - seemed an inadequate reason to reject $P b c a$.

Full-matrix refinement in $P b c a$ proceeded routinely to $R=0.056$ for 1671 reflections and 81 parameters, slightly higher than the 0.054 reported by Yano et al. (1993) (and reproduced by me) for 95 parameters in $P 2_{1} 2_{1} 2_{1}$. Presumably of greater significance is the goodness-of-fit value, which was 0.97 (according to my calculations) for the $P 2_{1} 2_{1} 2_{1}$ model and 0.90 for the revised, Pbca model. (I have no idea as to how the value could be less than 1.0.) The $O$ atoms were modeled as anisotropic in $P b c a$, but isotropic in $P 2_{1} 2_{1} 2_{1}$ (where, presumably, the correlations would have been intolerable). Late in the refinement, a difference map based on the low-order reflections - out to $\sin ^{2} \theta / \lambda^{2}=0.1 \AA^{-2}$ - indicated $\mathrm{H}$ atoms bonded to $\mathrm{O}(2)$ and $\mathrm{O}(5)$, as suggested by Yano et al. (1993); these atoms were included in the final refinements. In the last cycle, the maximum shift was $0.02 \sigma$.

Final Pbca coordinates are given in Table 1. They are more precise, by an average factor of about 5 , than those reported by Yano et al. (1993), due to the removal of near-singularities; they are surely more accurate as well. Bond lengths and angles within the $\mathrm{SiO}_{4}$ and the $\mathrm{O}-\mathrm{H} \cdots \mathrm{O}$ groups are given in Table 2 . Two items may warrant comment: (1) the shortness of the $\mathrm{Si}-\mathrm{O}(4)$ bond relative to $\mathrm{Si}-\mathrm{O}(1)$ and $\mathrm{Si}-\mathrm{O}(3)$ correlates with its environment, since $\mathrm{O}(4)$ is coordinated to only two $\mathrm{Ca}$ atoms, and accepts a very weak hydrogen bond $\left[\mathrm{O}(5) \cdots \mathrm{O}\left(4^{\mathrm{ii}}\right) 3.093\right.$ (4) $\AA$; symmetry code: (ii) $\frac{1}{2}+x, y, \frac{1}{2}-z$ ], whereas $\mathrm{O}(1)$ is coordinated to three $\mathrm{Ca}$ atoms, and $\mathrm{O}(3)$ is coordinated to two $\mathrm{Ca}$ atoms and accepts a strong hydrogen bond $\left[\mathrm{O}(2) \cdots \mathrm{O}\left(3^{\mathrm{i}}\right) 2.679\right.$ (4) $\AA$; symmetry code: (i) $\left.\frac{1}{2}-x, \frac{1}{2}+y, z\right]$; (2) the nonlinearity of the $\mathrm{O}(5)-$ $\mathrm{H}(5) \cdots \mathrm{O}\left(4^{\mathrm{ii}}\right)$ grouping reflects not only the weakness of the interaction but also the wish of $\mathbf{H}(5)$ to complete an approximate tetrahedron about $\mathrm{O}(5)$, which is also coordinated to three $\mathrm{Ca}$ atoms. Other details of the structure are approximately as described by Yano et al. (1993).

In deciding upon space group $P 22_{1} 2_{1}$, Yano et al. (1993) were undoubtedly influenced by Heller (1952), who had also rejected Pbca on the basis of apparent 
violations of the systematic absences. None of those three violations (209, 407 and 530) was among the six reported by Yano et al. As noted by Yano et al., the structure derived by Heller (1952) - an 'approximation' to the true structure, based on space group $P b c a$ - was grossly incorrect, leading to $\mathrm{Ca}-\mathrm{Ca}$ and $\mathrm{Ca}-\mathrm{Si}$ distances as low as $2.5 \AA$.

Table 1. Fractional atomic coordinates and isotropic or equivalent isotropic displacement parameters $\left(\AA^{2}\right)$

\begin{tabular}{|c|c|c|c|c|}
\hline \multicolumn{5}{|c|}{$U_{\mathrm{eq}}=(1 / 3) \sum_{i} \sum_{j} U_{i j} a_{i}^{*} a_{j}^{*} \mathbf{a}_{i} \cdot \mathbf{a}_{j}$} \\
\hline & $x$ & $y$ & $z$ & $U_{\text {eq }}$ or $B$ \\
\hline $\mathrm{Ca}(1)$ & $0.48415(7)$ & $0.16956(7)$ & $0.06863(7)$ & $0.0086(1)$ \\
\hline $\mathrm{Ca}(2)$ & $0.34570(7)$ & $0.00578(8)$ & $0.38878(6)$ & 0.0079 (1) \\
\hline $\mathrm{Si}$ & $0.16927(10)$ & $0.21286(10)$ & $0.15970(9)$ & $0.0067(1)$ \\
\hline$O(1)$ & $0.05605(26)$ & $0.13832(26)$ & $0.06504(25)$ & $0.0085(4)$ \\
\hline$O(2)$ & $0.24927(30)$ & $0.34579(29)$ & $0.07281(26)$ & $0.0122(5)$ \\
\hline $\mathrm{O}(3)$ & $0.29582(28)$ & $0.09944(28)$ & $0.19042(25)$ & $0.0106(4)$ \\
\hline$O(4)$ & $0.10182(29)$ & $0.29231(27)$ & $0.27970(23)$ & $0.0103(4)$ \\
\hline $\mathrm{O}(5)$ & $0.39398(29)$ & $0.45254(28)$ & $0.39616(27)$ & $0.0097(4)$ \\
\hline$H(2)$ & $0.238(7)$ & $0.438(7)$ & $0.110(6)$ & $3.7(16) \dagger$ \\
\hline $\mathrm{H}(5)$ & $0.406(8)$ & $0.413(8)$ & $0.339(7)$ & $4.9(20) \dagger$ \\
\hline
\end{tabular}

$\dagger$ Isotropic displacement parameter, $B$.
Table 2. Selected distances $(\AA)$ and angles $\left(^{\circ}\right)$

$\begin{array}{llll}\mathrm{Si}-\mathrm{O}(1) & 1.625(3) & \mathrm{O}(2)-\mathrm{Si}-\mathrm{O}(1) & 104.9(1) \\ \mathrm{Si}-\mathrm{O}(2) & 1.710(3) & \mathrm{O}(3)-\mathrm{Si}-\mathrm{O}(1) & 110.1(1) \\ \mathrm{Si}-\mathrm{O}(3) & 1.622(3) & \mathrm{O}(4)-\mathrm{Si}-\mathrm{O}(1) & 115.0(1) \\ \mathrm{Si}-\mathrm{O}(4) & 1.606(3) & \mathrm{O}(3)-\mathrm{Si}-\mathrm{O}(2) & 103.8(1) \\ & & \mathrm{O}(4)-\mathrm{Si}-\mathrm{O}(2) & 106.5(1) \\ \mathrm{O}(2)-\mathrm{H}(2) & 0.94(6) & \mathrm{O}(4)-\mathrm{Si}-\mathrm{O}(3) & 115.2(1) \\ \mathrm{H}(2) \cdots \mathrm{O}\left(3^{3}\right) & 1.74(6) & & \\ \mathrm{O}(5)-\mathrm{H}(5) & 0.73(8) & \mathrm{O}(2)-\mathrm{H}(2) \cdots \mathrm{O}\left(3^{\mathrm{i}}\right) & 174(6) \\ \mathrm{H}(5) \cdots \mathrm{O}\left(4^{4 i}\right) & 2.50(8) & \mathrm{O}(5)-\mathrm{H}(5) \cdots \mathrm{O}\left(4^{\mathrm{i}}\right) & 140(7)\end{array}$

Symmetry codes: (i) $\frac{1}{2}-x, \frac{1}{2}+y, z$; (ii) $\frac{1}{2}+x, y, \frac{1}{2}-z$.

Lists of structure factors and anisotropic displacement parameters have been deposited with the IUCr (Reference: CR1116). Copies may be obtained through The Managing Editor, International Union of Crystallography, 5 Abbey Square, Chester CH1 2HU, England.

\section{References}

Heller, H. (1952). Acta Cryst. 5, 724-728.

Yano, T., Urabe, K., Ikawa, H., Teraushi, T., Ishizawa, N. \& Udagawa, S. (1993). Acta Cryst. C49, 1555-1559. 